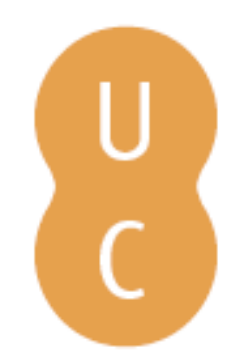

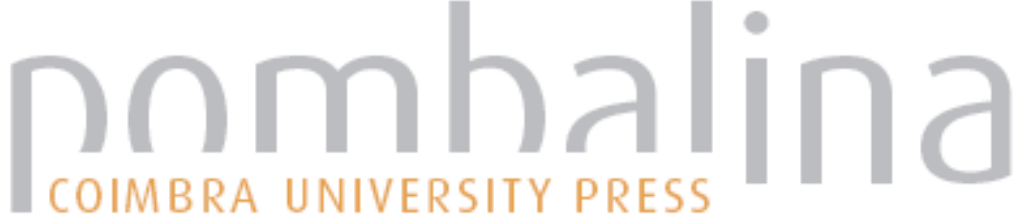

\section{Risk of injury in youth sports: role of psychological factors}

Autor(es): Kontos, Anthony P.

Publicado por: Imprensa da Universidade de Coimbra

URL

persistente: URI:http://hdl.handle.net/10316.2/38877

DOI: $\quad$ DOI:http://dx.doi.org/10.14195/978-989-26-1171-6_14

Accessed : $\quad$ 26-Apr-2023 05:48:49

A navegação consulta e descarregamento dos títulos inseridos nas Bibliotecas Digitais UC Digitalis, UC Pombalina e UC Impactum, pressupõem a aceitação plena e sem reservas dos Termos e Condições de Uso destas Bibliotecas Digitais, disponíveis em https://digitalis.uc.pt/pt-pt/termos.

Conforme exposto nos referidos Termos e Condições de Uso, o descarregamento de títulos de acesso restrito requer uma licença válida de autorização devendo o utilizador aceder ao(s) documento(s) a partir de um endereço de IP da instituição detentora da supramencionada licença.

Ao utilizador é apenas permitido o descarregamento para uso pessoal, pelo que o emprego do(s) título(s) descarregado(s) para outro fim, designadamente comercial, carece de autorização do respetivo autor ou editor da obra.

Na medida em que todas as obras da UC Digitalis se encontram protegidas pelo Código do Direito de Autor e Direitos Conexos e demais legislação aplicável, toda a cópia, parcial ou total, deste documento, nos casos em que é legalmente admitida, deverá conter ou fazer-se acompanhar por este aviso.

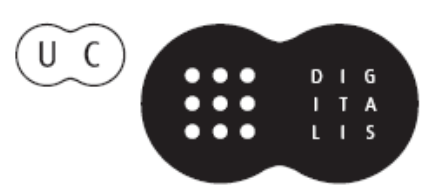



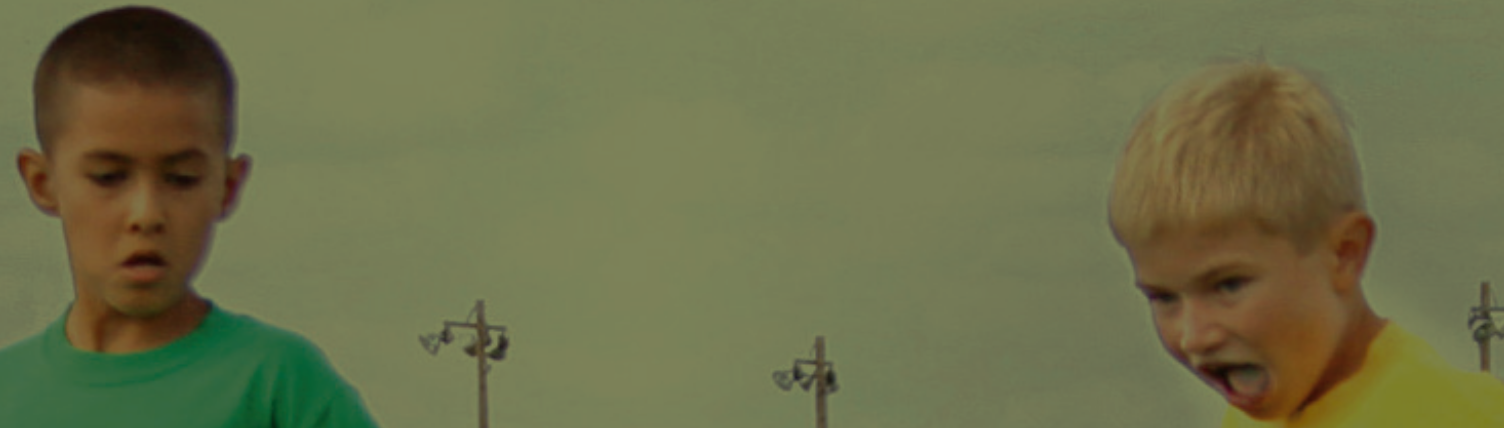

YOUTH SPORTS

\section{PARTICIPATION, $:$}

TRAINABHLTY TY

AND READINESSh

MANUEL J. COELHO E SILVA

ANTÓNIO J. FIGUEIREDO

MARIJE T. ELFERINK-GEMSER

ROBERT M. MALINA

EDITORS

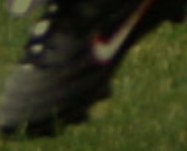

2. ${ }^{\circ}$ EDIÇÃO

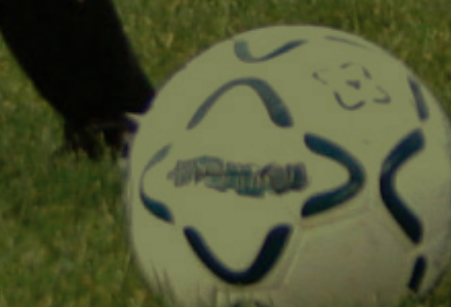

IMPRENSA DA

UNIVERSIDADE

DE COIMBRA

COIMBRA

UNIVERSITY

PRESS 


\section{CHAPTER 14: RISK OF INJURY IN YOUTH SPORTS - role of psychological factors}

Anthony P Kontos

\section{Questions to consider?}

- What are the risks of injury in youth sports?

- How do psychological factors affect the risk of injury among youth sport participants?

- How do other factors interact with psychological factors to influence the injury process?

\section{INTRODUCTION}

John is a 13 year-old youth soccer player who currently has a mild ankle sprain. This is his third injury during the past month. Previously, he incurred a contusion during a tackle of an opponent, and before that, he had a mild concussion after a collision with an opposing goalkeeper. John's coaches and parents are concerned about John's propensity to be injured. Why does John continue to be injured? Do his behaviors and thoughts influence the likelihood of him being injured? Are John's stress and anxiety levels affecting the likelihood that he is injured? Or is it that there are certain youth sport participants who, like John, have a certain set of personality characteristics that make them more likely than others to be injured?

Many of us would agree, anecdotally, that this last statement has some merit, as we all know athletes like John who seem to be injured more often than other athletes. However, the notion of an 'injury prone' (Lysens et al., 1989; Taerk, 1977) athlete or personality has not been supported empirically (see Personality section). Injury involves a multidimensional process influenced by a myriad of factors; among them, life stress, competitive anxiety, social support and other psychological factors. During the last decade, researchers and practitioners alike have focused considerable efforts toward understanding the psychological factors affecting the injury process in sport (Williams and Andersen, 1998). Most of these studies have focused on adult sport participants, at the exclusion of youth sport participants. As a result, much of 
what we suppose regarding the role of psychological factors in injury among youth is generalized from research on adult sport participants. Hence, the purpose of this chapter is to review the extant literature and discuss the psychological factors that are related to injury in sport. Information specific to youth sports and factors that interact with psychological factors in regard to injury will be explored. Additionally, this chapter will offer the reader a multidisciplinary framework from which to consider injury in youth sport. A brief overview of the inherent risks of injury in youth sport is presented first.

\section{RISK OF INJURY IN YOUTH SPORT}

Most studies of injury in youth sport have focused on adolescents (i.e., approximately 13-18 years), as they are a more readily accessible group for study. The limited information on youth (i.e., $<13$ years) sport participants is due to a variety of reasons including the informal nature of sports at the youth level, difficulty in gaining access to youth athletes, and unreliability of self-report data collection methods at this level. Consequently, much of the available information regarding the risk of sport injury for adolescents may have limited generalizability to youth sport participants under the age of 13 years. None the less, this information helps to frame the discussion of the role of psychological factors in sport injury risk for both adolescents and youth.

It is estimated that between 3 and 5 million injuries occur annually among 5- to 17-year-old sport participants in the United States (Bijur et al., 1995). These numbers translate to an annual injury risk rate of approximately 6-7 injuries/l 00 sport participants (Bijur et al., 1995). Injury risk rates vary by age, sex, and sport type. Regardless of sex, older (i.e., late adolescent) athletes, who typically are competing at more advanced levels, are more likely to be injured than younger athletes (Bijur et al., 1995). Research also indicates that males tend to have more injuries than females (Whieldon and Cerny, 1990). However, this finding belies the fact that females may have a greater risk of injury than males competing in the same or similar sports. Powell and BarberFoss (2000) reported that females had considerably higher respective rates of injury than males in the following sports: soccer, basketball, and softball/baseball. Moreover, females were more susceptible to certain injuries (e.g., ACL tears) than males (Powell and Barber-Foss, 2000). Sport injury statistics regarding the influence of sex are often misleading, as sport type interacts with sex to affect these findings. Specifically, females lack significant participation in or have no equivalent counterpart to sports such as American football, rugby, and hockey, all of which have relatively high rates of injury. Hence, the across sport sex comparisons of injury rates suggest that males have higher injury rates than females, when in fact, this is not always the case. 
Certain sports carry higher overall risks of injury for youth than other sports. In general, it is recognized that collision sports such as American football, rugby, and hockey have the highest rates of severe injuries (e.g., fractures, dislocations, spinal and head injuries) due to the purposeful contact that occurs on a regular basis between players in these sports (Nicholl et al., 1995; Powell and Barber-Foss, 1999). Contact sports such as soccer (Nicholl et al., 1995), basketball (Powell and Barber-Foss, 1999), and field hockey (Nicholl et al., 1995) also have a significant risk of injury associated with them. However, of greater importance to coaches, parents and athletes is that each sport is characterized by a specific type or location of injuries. For instance, one could logically infer that youth soccer players have a high risk of knee injuries due to the lateral lower body movements inherent to the sport, where as distance runners are more likely than soccer players to incur shin splints as a result of the repetitive motions of linear running on a hard surface. Research suggests that $A C L$ knee injuries, which often are the result of injury mechanisms involving lateral movements, are higher in soccer than in other sports (Powell and Barber-Foss, 2000). Participants in collision sports such as American football are at greatest risk for traumatic head injuries (Powell and Barber-Foss, 1999). In contrast, soccer players may be at risk for increased neurocognitive symptoms and impairment, and head injuries from heading (Kontos, 2002; Matser et al., 1999). However, given the current body of empirical knowledge, the relationship between heading and subsequent longterm development of symptoms and injury is at best speculative. Regardless, these examples illustrate the importance of sport type in determining specific injury risk in youth sports.

Although sport type, sex, and age play an important role in determining injury risk in specific sports, they are factors that are essentially out of the control of coaches, parents and athletes. Psychological factors, on the other hand, not only play a significant role in affecting injury outcomes across different sports; they are also amenable to change and prevention strategies.

\section{PSYCHOLOGICAL FACTORS AND INJURY IN SPORT}

The relationship between psychological factors and injury in sport has been examined empirically since the 1970s (e.g., Bramwell et al., 1975). In spite of the nearly three decades of research on psychological factors and injury in sport, researchers have uncovered few consistent relationships. The inconsistent findings in the literature are a product of poor methodologies (e.g., use of retrospective reporting of data), the lack of consensus on operational definitions of injuries and psychological factors, and incomplete or inappropriate statistical analyses (i.e., lack of moderator analyses). Despite these issues, consistent empirical support revolving around life stress and 
related factors such as social support/coping, emotional states and competitive anxiety has emerged (Junge, 2000; Williams and Andersen, 1998).

The most prominent theoretical framework for understanding the relationship between psychological factors and injury in sport is the stress model of sport injury (see Figure I: Williams and Andersen, 1998). The stress model proposes that sport injuries are a result of athletes' stress responses to specific athletic situations. The stress response consists of an interaction between an athlete's cognitive appraisal of the situation and their physiological/attentional changes. For example, a rugby player who cognitively appraises an opponent as violent and malicious may respond with muscle tension (i.e., physiological) and attentional focus narrowing, which may then set the stage for subsequent injury. This stress response is moderated by three interactive factors: (a) personality, (b) history of stressors, and (c) coping resources. The model indicates that interventions, such as cognitive restructuring, imagery or relaxation training also moderate the stress response. An athlete's stress response ultimately determines injury outcome.

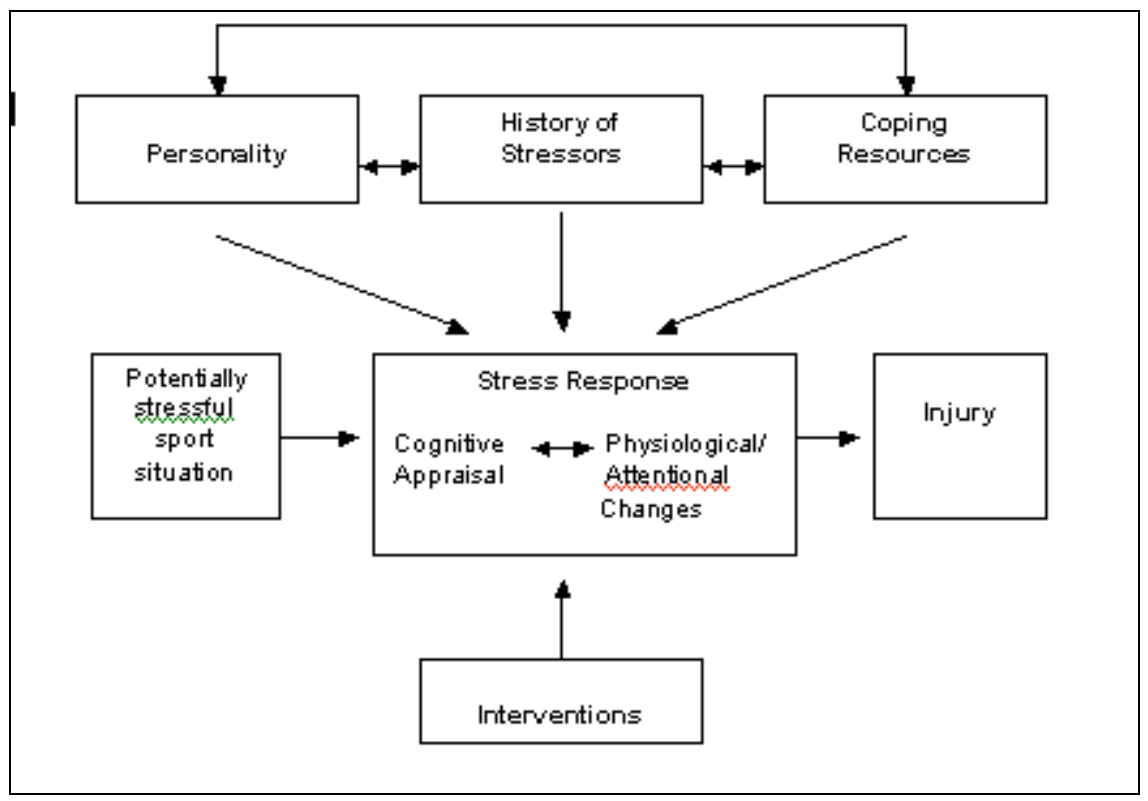

Figure I. The stress model of injury in youth sport

Researchers have found support for a variety of factors in the stress model that influence the likelihood of injury among sport participants such as life stress (see Kontos and Foret, 200I for a meta-analytic review of the life-stress and injury relationship), sensation seeking (e.g., Smith et al., 1992), and social 
support (e.g., Andersen and Williams, 1997). A review of the findings related to these and other history of stressors, coping resources, and personality factors is presented below. Much of the information reviewed in the following sections is based on studies of adult sport participants. Wherever possible, studies on youth sport participants and additional information relating to youth are provided.

\section{HISTORY OF STRESSORS}

The most consistently supported findings in the psychology of injury literature pertain to the relationship between psychosocial stress and injury. Stress has been delineated into life stress events (e.g., death, loss of a friend) and daily hassles (e.g., traffic, communication with teammates). For the purpose of this discussion, the term life stress will refer to both types of stressors. Life stress, in particular, stress related to sport, is proposed to affect injury likelihood through the stress response (Williams and Andersen, 1988). Unfortunately, few studies (e.g., Andersen, 1988; Andersen and Williams, 1997) have directly assessed the stress response, resulting in a tenuous assumption of its efficacy on the part of researchers (Williams and Andersen, 1998). A study by Andersen (1988) reported that stress increased muscle tension, which in turn may lead to an increase risk for injury. Andersen and Williams (1997) found that athletes with high negative life stress experienced greater attentional focus narrowing (i.e., physiological stress response) and were more likely to incur injuries than non-stressed athletes. The cognitive appraisal component of the stress response may also be affected by life stress, though this relationship has not yet been examined empirically.

Narrative reviews of the life stress and sport injury literature have suggested that the majority of studies support a positive relationship between life stress and injury (see Williams and Andersen, 1998; Williams and Roepke, 1993). A recent meta-analytic review of the life stress injury relationship provided support for a low to moderate positive relationship between life stress and injury (Kontos and Foret, 200 I). However, this relationship was only applicable to negative (e.g., demotion in sport, death of a friend) and total (i.e., negative and positive) life stress. In contrast to previous research (Blackwell and McCullagh, 1990; Petrie, 1993) the relationship between positive (e.g., promotion in sport, new friends) life stress and injury was near zero. Therefore, one can infer that a large quantity of life stress and life stress that is perceived as negative by athletes play a greater role in the injury process than does positive life stress. This finding echoed the results of previous research on the role of negative and total life stress in injury in sport (e.g., Passer and Seese, 1983; Smith et al., 1990). 
Youth sport presents a unique set of potential stressors that may adversely affect injury outcomes. The pressure to win, and consequently, not lose, is a significant stressor among youth in sport (Smoll and Smith, 1990). The pressure to win at all costs may encourage youth to engage in risk taking behaviors that may lead to injury. The stress related to being successful can result from pressure on young sport participants to maintain status on a team (i.e., starter), gain a scholarship or professional career, or please those around them. Parents are a common source of stress for youth in sport (Scanlan, 1986). This stress can be a result of parents' over-identification with their child's youth sport endeavors. Parents who attempt to live vicariously through their child often place tremendous stress on the outcomes of youth sport, which creates stress for their child. Coaches also have substantial direct contact with youth sport athletes, and can affect their perceptions considerably. A negative coaching style (e.g., punishment, lack of reward, negative reinforcement) adds stress to the youth sport setting. In fact, negative coaching behaviors have been linked directly to an increased risk of injury in youth sport (Kontos, 1995). Although youth sport participants are susceptible to stress from many sources, it is often their ability, or inability, to cope with stress that determines the effects it has on injury outcomes.

\section{COPING RESOURCES}

Stress is an inevitable part of youth sport. If a youth sport participant does not cope well with stress, their likelihood for injury will increase. Coping can take several forms: social support from family and peers, psychological coping such as stress management, and general coping such as good nutrition (Williams and Andersen, 1998). Regardless of the source, it appears that poor coping resources generally increase the likelihood of injury in sport (Hanson et al., 1992; Petrie, 1992; Williams et al., 1986). Williams and Andersen (1997) found that low social support increased the stress response and subsequent likelihood of injury. Coping is particularly salient for youth sport because so few youth have developed adequate coping resources before entering adulthood. Moreover, many of the potential coping mechanisms used by adults are used infrequently by youth. For example, youth sport participants would benefit from social support from knowledgeable others such as coaches and parents; however, as discussed previously, parents or coaches may be the main sources of stress for many youth sport participant. Although peer social support and coping is available to youth, it may be equally ineffective, as their peers are likely to possess similarly limited coping resources. Coping resources, the effects of stress, and injury outcomes are also influenced by an athlete's personality. 


\section{PERSONALITY}

Much of the early research on psychological factors and injury in sport focused on personality factors (e.g., Lysens et al., 1989; Taerk, 1977). These early studies sought to characterize an 'injury prone' personality type. Although these and subsequent studies failed to uncover any specific 'injury prone' personality, they did provide support for the relationship between certain personality traits and injury in sport (Junge, 2000). For instance, researchers (Backx et al., 1991; Straub, 1982) have suggested that certain athletes are 'high-risk' individuals because they seek sensation in sport. These athletes are subsequently more likely to engage in risk-taking behaviors than athletes who are not 'high-risk'. Smith et al. (1992) observed that athletes low in sensation seeking reported more negative life-stress and had higher incidences of injury than those high in sensation seeking. Their findings suggest that sensation seeking (i.e., 'high risk' individuals) athletes, who actively seek out 'high risk' situations, have an inherently greater ability to deal with the stress associated with these situations. In turn, this may predispose sensation seekers to better cope with and prepare for potentially injurious or otherwise dangerous situations, thus limiting their likelihood for injury. Sensation seeking athletes may also engage in 'calculated' or informed risk taking, where contingency plans are developed to proactively deal with potential negative circumstances related to risk taking. However, the relationship between sensation seeking and risk taking behaviors in sport has not been confirmed.

In other research, the propensity for risk taking among certain athletes was found to be a key psychological factor in the determination of injury outcomes in sport (Jackson et al., 1977; Taimela et al, 1990). A more recent foray examining personality and injury in sport supported a similar relationship between being 'tough minded' (i.e., assertive, confident, and independent) and incurring more severe injuries (Wittig and Schurr, 1994). The researchers speculated that their findings might have been indicative of 'tough minded' athletes taking more risks than other athletes. These findings are in contrast to the findings regarding sensation seeking mentioned above, and may be reflective of 'uncalculated' risk taking on the part of the athletes in the Wittig and Schurr (1994) study. A direct link between sensation seeking type motives, risk taking behaviors and injury needs to be explored to better determine the interrelationship among these factors. It may be the type of risk taking (i.e., 'calculated' vs. 'uncalculated') that athletes engage in that is most important in determining injury outcomes. Regardless, these findings may be particularly salient among adolescent sport participants because sensation seeking and high risk (e.g., driving fast, drug use) behaviors increase linearly with age in adolescence (Brenner and Collins, 1998). Unfortunately, during the last few years, researchers have all but abandoned personality factors in relation to injury in sport. Research related to risk taking behaviors and 
perceived risk, however, has begun to emerge as a promising area of inquiry into the psychology of sport injury.

\section{PERCEIVED RISK AND RISK TAKING}

During the course of any sport event, young athletes are constantly making assessments of the environment. One of the assessments that athletes make pertains to their perceptions of risk of injury, or 'fear of injury'. Researchers have suggested that 'fear of injury' is a specific personality trait (i.e., injury trait anxiety) related to sport trait anxiety (e.g., Kleinert, 2002). From this perspective, injury trait anxiety would be included in the personality component of the stress model of injury. Other researchers, however, contend that perceived risk of injury represents a more situation-specific factor that is based on athletes perceptions of: (a) probability of injury- a cognitive assessment of injury likelihood, (b) worry/fear of injury- an assessment of negative emotion related to being injured, (c) perceived control over injury outcomes, and (d) consequences of injury outcomes (Kontos, 2002; Short et al., 200 I). This perspective suggests that perceived risk of injury represents the cognitive appraisal portion of the stress response component of the stress model of injury. Perceived risk of injury is proposed to affect an athlete's decision-making process regarding risk taking behaviors in sport (Kontos, 2000). It is most likely that situation specific perceptions of risk of injury interact with an athlete's sport trait injury anxiety to influence injury outcomes.

Researchers have yet to assess the direct effects of sport injury trait anxiety on the injury process. However, several trends in regard to perceived risk of injury and risk taking have emerged. Namely, a high perceived risk of injury (i.e., probability, worry, and lack of control over injury outcomes) has been linked to increased injury risk (Kontos, 2002). Although researchers have hypothesized an inverse relationship between perceived risk and risk taking, this relationship has not been empirically supported in youth sports (Kontos, 2000). Risk taking has been found to be related to injury in youth in non-sport environments (Potts et al., 1995), however, risk taking has yet to be reliably assessed in youth sport. Perceived risk of injury has also been linked to selfconfidence.

\section{SELF-CONFIDENCE AND PERCEIVED RISK}

According to Bandura (1997), athletes who inaccurately perceive themselves to be high in ability are likely to have inflated confidence (i.e., overconfidence) in attaining desired outcomes in a given situation. Consequently, overconfident athletes may engage in more risk-taking behaviors because they are confident in attaining a positive outcome (i.e., not being injured) from their behaviors. Overconfidence in this context is analogous to perceived invincibility. In 
research with youth soccer players, Kontos (2000) found that risk taking was highest among overconfident athletes. Overconfident athletes were not, however, at greater risk of injury than other athletes. In contrast, athletes who underestimated their abilities (under-confident) and perceived high risk of injury were at significantly greater risk of injury than other athletes (Kontos, 2000). Short et al (200I) reported an inverse relationship between perceived risk and self-confidence among collegiate athletes. Hence, young athletes who have high perceptions of risk appear to lack confidence in their sport skills and are at greater risk of injury in sport.

\section{FEAR OF REINJURY}

Athletes who return to sport from an injury too early may also be at increased risk for a subsequent injury. The increased risk of injury may be related to athlete's perceptions of the likelihood of potentials outcomes (i.e., reinjury) of their return to sport. Often, these athletes appear to be physically ready to return to sport. Mentally, however, they may lack pre-injury levels of confidence, have a greater fear of injury, and be hesitant in their approach to their sport (Petitpas and Danish, 1995; Williams and Roepke, 1993). Consequently, coaches, parents and athletes should monitor mental, as well as physical aspects of recovery from injury to determine an athlete's overall readiness to return to sport.

\section{INTERACTION OF PSYCHOLOGICAL AND OTHER FACTORS}

Although psychological factors play a significant role in determining injury in youth sport, these factors typically account for $15-40 \%$ of the variance in injury outcomes (Kontos and Foret, 200I; Williams and Andersen, 1998). This finding suggests that psychological factors do not act alone in influencing injury. When determining the risk of injury in youth sport it is important to examine the interactions among maturation/biology, biomechanic, physical/environmental, socio-cultural and psychological factors. For example, as Morano and Malina discuss in Chapter 14, biology (i.e., physical size) and maturity are key factors to consider when determining injury risk in youth sport.

\section{INTERACTIVE EFFECTS OF NON-PSYCHOLOGICAL FACTORS ON PERCEIVED RISK}

The perceived risk of injury in sport literature provides a good example of the interactive effects of biology/maturation, biomechanic and socio-cultural, and psychological factors on injury in youth sport. For instance, young athletes who are physically larger than their peers appear to be more confident in sports and engage in more risk taking than average or smaller size athletes (Kontos et 
al., 1999; Kontos, 2000). This relationship appears to be influenced more by maturation status (i.e., early, average, late) than physical size. Specifically, early maturers are more likely than average or late maturers to engage in risk taking behaviors in sport regardless of physical size (Kontos, 2000).

Sex also plays an important role in the risk of injury among youth sport athletes. Males are more confident (often over confident) and perceive less risk, and engage in more risk taking in youth sport than females (Kontos, 2000; 2002). Coaches and parents (i.e., socio-cultural factors) may exacerbate these effects by focusing more attention on skill development among female athletes and less attention on strength and conditioning, two factors that reduce the risk of injury in sport. The socialization of males toward aggression in youth sport may also influence this relationship.

As discussed earlier, overconfident athletes engage in risk taking in sport. The use of protective equipment such as helmets, shin guards, and mouth guards may inflate the confidence of athletes and the likelihood that athletes will engage in reckless or risk behaviors in sport. The added protection afforded by these biomechanic-related devices may reduce perceptions of risk of injury and give athletes a feeling of invincibility. Hence, biomechanic devices designed to minimize the physical risk of injury may result in an increased behavioral risk of injury.

Other factors also must be considered when examining the injury process in youth sport. Biomechanic factors such as the location of females' knee joints relative to their hips (i.e., ' $q$ angle'), an imbalance in strength in the hamstrings compared to the quadriceps, and neuromuscular control (i.e., agility) problems are related to an increased risk of knee injuries for females (Bonci, 1999; Ireland, 1999). Socio-cultural factors such as: the behaviors of significant others (e.g., coaches: Kontos, 1995; Shields et al., 1995); expectations and modeling of aggressive or violent behaviors (Mugno and Feltz, 1985; Stuart and Ebbeck, 1995); and sport-specific norms and expectations such as sanctioned violence in collision sports like rugby, hockey and American football (Shields and Bredemeier, 1995) may also increase the risk of injury in youth sport. The previous examples of the interactions of multiple factors on injury highlight the need for a multidimensional approach to understanding the risk of injury in youth sport.

\section{A NEW MULTIDISCIPLINARY FRAMEWORK FOR UNDERSTANDING INJURY IN YOUTH SPORT}

As mentioned previously, researchers have focused considerable attention on the psychological factors related to injury in sport (Williams and Andersen, 1998). The stress model of injury is the most commonly used theoretical 
framework for examining the psychological factors related to sport injury. Although the stress model of injury has provided an empirically valid theoretical framework for examining injury in sport, it was designed for use with adult sport populations. Moreover, the stress model of injury does not consider the myriad of psychobiosocial and other factors affecting the injury process among youth sport participants. As Williams and Andersen noted in their 1998 review and revision of the stress model, researchers should consider non-psychological as well as psychological factors in determining injury outcomes. Hence, a new multidisciplinary revision of the stress model of injury in youth sport is proposed in Figure 2.

The new multidisciplinary model of youth sport injury integrates the basic mechanism and premise of the stress model together with biology/maturation, biomechanic, physical/environmental, and socio-cultural factors to allow for a more comprehensive examination of injury in youth sport. The new model begins with the inherent injury risk associated with a specific sport situation. The inherent injury risk is determined by the sport environment (e.g., sport type, playing conditions), and the biomechanic and physical characteristics of the athlete. The inherent risk leads to a revised stress response, which includes four interactive components: (a) cognitive appraisal (e.g., perceived risk), (b) physiological response, (c) behavioral response (e.g., risk taking), and (d) emotional response (e.g., fear). The stress response is then moderated by three interactive factors: socio-cultural (e.g., coaches, culture) psychological (e.g., personality), and maturation/biology (e.g., sex, maturity). Interventions such as imagery and stress management also moderate the stress response and affect the inherent injury risk. The revised stress response directly determines injury outcomes. Once an injury outcome (e.g., injured vs. uninjured) has occurred, it becomes a previous injury experience and affects the inherent injury risk, and moderates the athlete's subsequent stress response. This feedback loop continues to evolve as the athlete experiences injuries both directly and indirectly (i.e., vicariously through others or the media). The multidisciplinary model of injury in youth sport offers researchers and practitioners alike a comprehensive framework from which to assess injury risk in youth sport. 


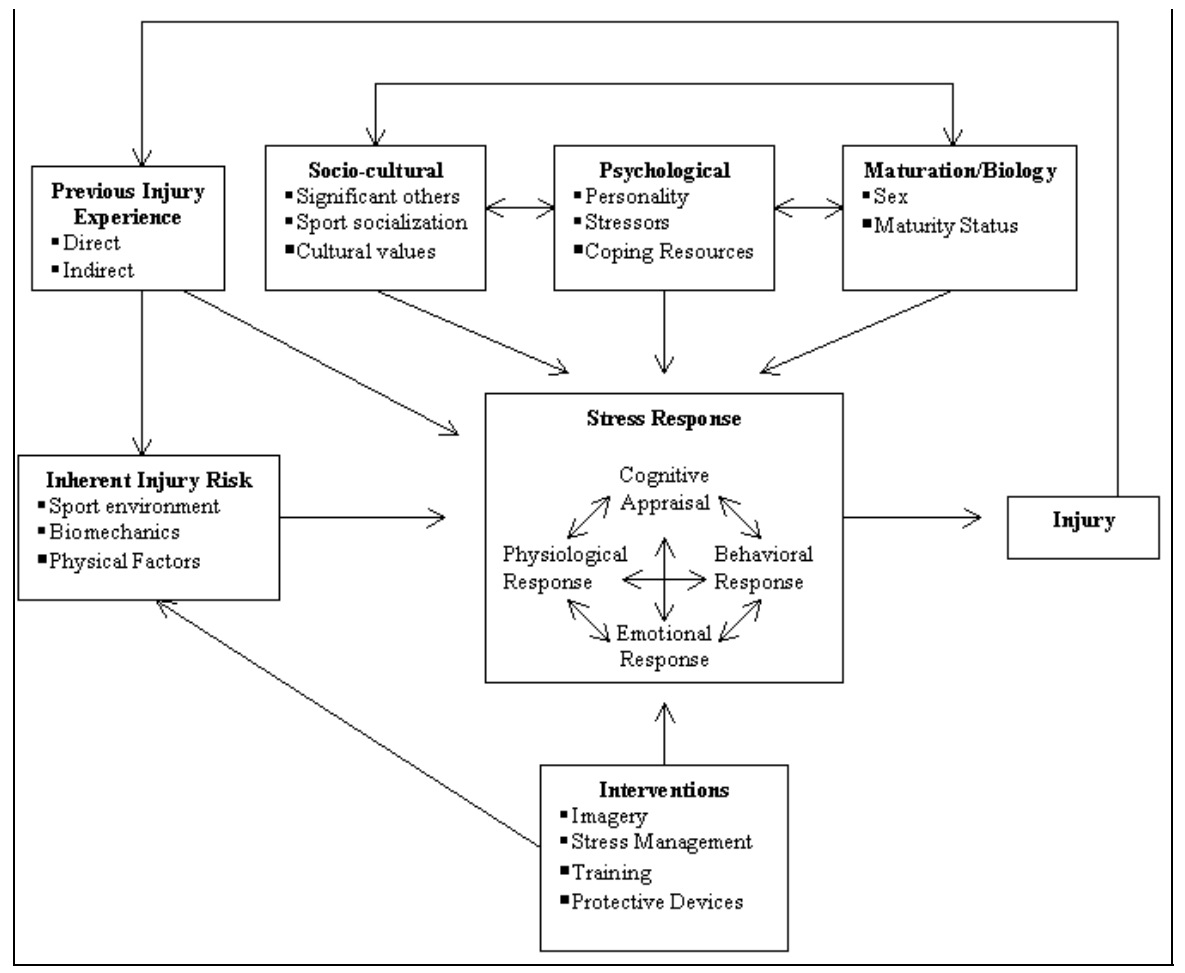

Figure 2. A multidisciplinary revision of the stress model of injury in youth sport.

\section{CONCLUSION}

Psychological factors appear to play a significant role in the determination of injury among youth sport participants. Research has supported strong relationships between factors such as perceived risk (Kontos, 2000; Short et al., 200I) and life stress (Kontos and Foret, 200I; Williams and Andersen, 1998; Williams and Roepke, 1993), and injury. However, additional psychological (e.g., sensation seeking, injury trait anxiety) and other (e.g., maturation, socio-cultural) factors affecting the potential for injury among youth sport participants need to be examined. Psychological and other factors related to injury in youth sport should be investigated using an interactional approach such as the one presented earlier in the multidisciplinary model of youth sport injury. Future research should also compare the effects of these factors on youth- and adolescent-aged populations, as developmental differences may influence injury outcomes. Finally, the results of research on the psychological factors related to injury in youth sport should ultimately be used to develop prevention strategies such as behavioral guidelines, risk awareness, stress reduction and increased self-confidence. 


\section{REFERENCES}

Andersen MB, Williams JM (1997). Athletic injury, psychosocial factors, and perceptual changes during stress. Unpublished manuscript.

Andersen MB, Williams JM (1988). A model of stress and athletic injury: Prediction and prevention. Journal of Sport and Exercise Psychology. 10: 294-306.

Backx FJ, Beijer HJ, Bol E, Erich WB (199I). Injuries in high-risk persons and high-risk sports. The American Journal of Sports Medicine. 19: 124- 130.

Bandura A (1997). Self-efficacy: The exercise of control. New York: Freeman and Co.

Bijur PE, Trumble A, Harel Y, Overpeck MD, Jones D, Scheidt PC (1995). Sports and recreation injuries in US children and adolescents. Archives of Pediatric and Adolescent Medicine. 149: 1009-1016.

Blackwell McCullagh (1990). The relationship of athletic injury to life-stress, competitive anxiety, and coping resources. Athletic Training. 25 (I): 23-27.

Bonci CM (1999). Assessment and evaluation of predisposing factors to anterior cruciate ligament injury. Journal of Athletic Training. 34: I 55- 164.

Bramwell ST, Matsuda M, Wagner NH, Holmes TH (1975). Psychological factors in athletic injuries: Development and application of the Social and Athletic Readjustment Rating Scale (SARRS). Journal of Human Stress. $6: 3-5$.

Brenner ND, Collins JL (1998). Co-occurrence of health-risk behaviors among adolescent in the United States. Journal of Adolescent Health. 22 : 209-2I 3.

Hanson SJ, McCullagh P, Tonymon P (1992). The relationship of personality characteristics, life stress, and coping resources to athletic injury. Journal of Sport and Exercise Psychology. 14: 262-272.

Ireland ML (1999). Anterior cruciate ligament injury in female athletes: Epidemiology. Journal of Athletic Training. 34: I50- I54.

Jackson DW, Jarrett H, Bailey D, Kausek J, Swanson J, Powell JW (1978). Injury prediction in the young athlete: A preliminary report. American Journal of Sports Medicine. 6: 6-14.

Junge A (2000). The influence of psychological factors on sports injuries: Review of the literature. American Journal of Sports Medicine. 28: SIO-SI 5.

Kleinert J (2002). An approach to sport injury trait anxiety: Scale construction and structure analysis. European Journal of Sport Science. 2: 1 - 12.

Kontos AP (2000). The effects of perceived risk. risk taking behaviors. and body size on injury in youth sport. Unpublished doctoral dissertation. Michigan State University. East Lansing. Ml.

Kontos AP (1995). Perceptions of coaching behaviors and selected variables on injury occurrence in female youth soccer players. Unpublished master's thesis. Michigan State University. East Lansing. MI.

Kontos AP (2002). Psychosocial antecedents of heading exposure, concussion and neurocognitive symptoms among adolescent soccer players. Paper presented at the New Developments in Sports Concussion Conference. Pittsburgh. PA.

Kontos AP, Foret KL (200I). A meta-analytic review of the life stress and injury relationship in sport. Paper presented at the Association for the Advancement of Applied Sport Psychology Conference. Orlando. FL. 
Kontos AP, Malina RM, Feltz DL (1999). The development and validation of the Perception of Risk of Injury in Sports Scale (PRISSc). Presentation at the Youth Sport in the $2 I^{\text {st }}$ Century Conference. Michigan State University. East Lansing. MI.

Lysens RJ, Ostyn MS, Vanden Auweele Y, Lefevre J, Vuylsteke M, Renson L (1989). The accident-prone and overuse-prone profiles of the young athlete. American Journal of Sports Medicine. 17: 612-619.

Matser JT, Kessels AGH, Jordan BD, Lezak MD, Troost J (1999). Chronic traumatic brain injury in professional soccer players. Neurology. 5 I: 791-796.

Mugno DA, Feltz DL (1985). The social learning of aggression in youth football in the United States. Canadian Journal of Applied Sport Sciences. 10: 26-35.

Nicholl JP, Coleman P, Williams BT (1995). The epidemiology of sports and exercise related injury in the United Kingdom. British Journal of Sports Medicine. 29: 232-238.

Passer MW, Seese MD (1983). Life-stress and athletic injury: Examination of positive versus negative events and three moderator variables. Journal of Human Stress. 9: I 16 . 6 .

Petitpas A, Danish S (1995). Caring for injured athletes. In S Murphy (Ed.). Sport psychology interventions (pp. 255-28I). Champaign. IL: Human Kinetics.

Petrie TA (1993). The moderating effects of social support and playing status on the life stress-injury relationship. Journal of Applied Sport Psychology. 5: I- 16.

Petrie TA (1992). Psychosocial antecedents of athletic injury: The effects of life stress and social support on female collegiate gymnasts. Behavioral Medicine. 18: 127- 138.

Powell JW, Barber-Foss KD (2000). Sex-related injury patterns among selected high school sports. American Journal of Sports Medicine. 28: 385-398.

Powell JW, Barber-Foss KD (1999). Injury patterns in selected high school sports: A review of the 1995-1 997 seasons. Journal of Athletic Training. 34: 277-284.

Potts R, Martinez IG, Dedmon A (1995). Childhood risk taking and injury: Self-report and informant measures. Journal of Pediatric Psychology. 20 (I): 5- 12.

Scanlan TK (1986). Competitive stress in children. In MR Weiss, D Gould (Eds.). Sport for children and youths. Champaign. IL: Human Kinetics. Pp: I I3- I I 8

Shields DL, Bredemeier BJ (1995). Character development and physical activity. Champaign. IL: Human Kinetics.

Shields DL, Bredemeier BJ, Gardner DE, Bostrom A (1995). Leadership. cohesion. and team norms regarding cheating and aggression. Sociology of Sport Journal. 12: 324336.

Short S, Muir V, Eickhoff D, Kontos AP, Short M (200I) Relationships among perceptions of risk of injury, fear of injury, and confidence in avoiding injury in collision/contact sports. Paper presented at the North American Society for the Psychology of Sport and Physical Activity Conference. St. Louis. MO.

Smith RE, Ptacek JT, Smoll FL (1992). Sensation seeking, stress, and adolescent injuries: A test of stress-buffering, risk-taking, and coping skills hypotheses. Journal of Personality and Social Psychology. 62: 1016 -1024.

Smith RE, Ptacek JT, Smoll FL (1990). Conjunctive moderator variables in vulnerability and resiliency research: Life stress, social support and coping skills, and adolescent sport injuries. Journal of Personality and Social Psychology. 58: 360-369.

Smoll FL, Smith RE (1990). Psychology of the young athlete: Stress-related maladies and remedial approaches. Pediatric Clinics of North America. 3: I 021 - 1046.

Straub WF (1982). Sensation seeking among high and low risk male athletes. Journal of Sport Psychology. 4: 246-253. 
Stuart ME, Ebbeck $V$ (1995). The influence of perceived social approval on moral development in youth sport. Pediatric Exercise Science. 7: 270-280.

Taerk G (1977). The injury prone athlete: A psychosocial approach. Journal of Sports Medicine and Physical Fitness. 17: 187- 194.

Taimela S, Osterman L, Kujala U, Lehto M, Korhonen T, Alaranta H (1990). Motor ability and personality with reference to soccer injuries. Journal of Sports Medicine and Physical Fitness. 30: 194-201.

Whieldon TJ, Cerny FJ (1990). Incidence and severity of high school athletic injuries. Athletic Training. 25: 344-349.

Williams J, Andersen M (1998). Psychosocial antecedents of sport injury: Review and critique of the stress and injury model. Journal of Applied Sport Psychology. 10: 5-25.

Williams J, Roepke N (1993). Psychology of injury and injury rehabilitation. In RN Singer, LK Tennant, M Murphey (Eds.). Handbook of research on sport psychology (pp. 8I5-839). New York: McMillan.

Williams JM, Tonymon P, Wadsworth WA (1986). Relationship of stress to injury in intercollegiate volleyball. Journal of Human Stress. 12: 38-43.

Wittig AF, Schurr KT (1994). Psychological characteristics of women volleyball players: Relationships with injuries, rehabilitation, and team success. Personality and Social Psychology Bulletin. 20: 322-330. 